\title{
Mujeres mayores en la publicidad radiofónica: una presencia silenciada
}

\section{Old Women in Radio Advertisement: a Censored Presence}

\author{
María Teresa Piñeiro Otero \\ Universidade da Coruña, España \\ teresa.pineiro@udc.es
}

\section{Resumen}

El progresivo envejecimiento de la población en la sociedad occidental, junto con el incremento de su calidad de vida, ha propiciado la aparición de una nueva tipología de consumidores: la tercera edad. No obstante, la publicidad parece remisa a incorporar a su imaginario representaciones de personas mayores que se alejen del estereotipo del afable abuelo. Esta situación se hace especialmente patente en las representaciones femeninas, cuya ausencia es tan palpable como el abuso que los anuncios publicitarios hacen de las imágenes de mujeres más jóvenes.

El presente artículo estudia el tratamiento que la publicidad radiofónica española da a las mujeres mayores, especialmente en lo que se refiere a la utilización que los anuncios sonoros realizan de las presentaciones femeninas en general.

Palabras clave: Publicidad, radio, representaciones, mujeres, estereotipos, vejez

\begin{abstract}
Progressive aging of Western societies' population and the increase of life quality, have propitiated a new kind of consumers: old age people. Nonetheless, advertisement is reluctant to show old people but as the old-kind-grandpa stereotype. This situation is especially clear in the case of old female representations, whose absence is as important as the abuse of younger women in advertisement. The aim of this paper is to study old women stereotypes on Spanish radio advertising, and to make comparison with radio women representations in general.
\end{abstract}

Keywords: Advertising, radio, representations, women, stereotypes, old age 


\section{Introducción}

El envejecimiento demográfico y la situación de la llamada "tercera edad" han pasado, en las últimas décadas, a convertirse en un tema de relevancia en las agendas de los gobiernos de las sociedades occidentales. Esta situación de progresivo envejecimiento que muestra características comunes a todas las sociedades desarrolladas (y que se empieza a vislumbrar en aquellos países en vías de desarrollo), se ha convertido en uno de los elementos definitorios de la sociedad del siglo XXI; sociedad en la que, por primera vez, la población que se encuentra en la vejez ha logrado equipararse a la población joven (Naciones Unidas, 2000).

El incremento de la esperanza de vida y la calidad en la que se desarrolla la misma ha supuesto una dilación del último ciclo vital, con una repercusión directa en la prolongación del período de adulto hasta la llegada de la "vejez" propiamente dicha. Este segmento de población "madura" continúa mostrando determinadas conductas de carácter social y económico, la más relevante es el desarrollo de un consumo activo de productos y servicios, sin precedentes en décadas anteriores. Una situación que dificulta cada vez más asociar esta población madura con la concepción clásica de la vejez o, siguiendo a Simone de Beauvoir, con la idea del individuo como un desecho en los quince-veinte últimos años de su vida (1983:13).

Lo que la prolongación de la existencia significa es que tendremos que acostumbrarnos a tratar con cuerpos envejecidos, y que nuestra identidad del "yo" se instale en la idea de que pasaremos tantos años vivas después del climaterio, que ser vieja será tan normal como ser joven (Durán, 2006: 468).

La propia imagen de la vejez, cuya reconstrucción discursiva traspasa la concepción de una etapa vital a una colectividad social concreta construida de modo homogéneo como un grupo compacto, se fundamenta en características negativas como la soledad y la dependencia; caracterización que activa un grupo de estereotipos muy concretos (Lehr, 1980).

En este sentido, el estudio de una determinada representación publicitaria, como la de la vejez que se propone para este artículo, supone una aproximación de la consideración social que tiene la senectud y los actores implicados en nuestra sociedad; una consideración que se sitúa al margen la situación de la vejez y las personas mayores en la realidad.

\section{La construcción publicitaria de la vejez desde una perspectiva de género}

La prolongación del período vital correspondiente a la vejez, conjuntamente con la revelación de tendencias heterogéneas en los individuos pertenecientes a este grupo, ha provocado la necesidad de redefinición tanto del concepto como de las fronteras que definen a esta etapa (Rueda citado en Parales y Dulce Ruiz, 2002). En efecto, la concepción de la vejez se fundamenta en una serie de criterios e indicadores de carácter ambiguo, que están provocando que cada vez sea más complejo 
tomar la edad como un definidor cuando se está intentando definir una realidad tan heterogénea y compleja como una etapa de la vida humana (Rey, 1999).

No obstante, frente a esta necesidad manifiesta de reconceptualizar la vejez y las concepciones vigentes en torno a las personas ancianas como grupo social, la publicidad se muestra remisa a actualizar su imaginario relativo a la senectud (Freixas, 1998). Un imaginario cuya estabilidad le permite alcalzar el maximun comunicativo, al basarse en representaciones fácilmente comprensibles, próximas a aquellas concepciones socialmente admitidas sobre un determinado grupo social; a aquellas "imágenes mentales" que comparte una determinada colectividad (Lippmann, 2004).

Inclusive en un momento como en el actual, en el que las personas mayores ya no responden a la concepción beauvoriana de "desechos" (Beauvior, 1983), sino que participan activamente en la sociedad, resulta llamativo que la publicidad evite la vejez o la canalice mediante el sempiterno rol de abuelo afable o abuela cocinera-artesana.

Esta infrarrepresentación de las personas ancianas en la publicidad resulta una cuestión de especial relevancia si se atiende al papel que presenta la publicidad en el proceso de formación de la persona $y$, por tanto, en la configuración y perpetuación de unas determinadas imágenes y creencias (Santiso, 2001: 46).

La representación que los medios de comunicación y la publicidad realizan de la vejez y de la mediana edad, invade la conciencia de las personas creando un imaginario en torno a la edad, que supone uno de los núcleos del temor a envejecer debido a su vinculación con el rechazo y la devaluación de la persona (Freixas, 1998).

Del mismo modo que resulta pernicioso el abuso que la publicidad realiza de las mujeres como sujetos y como objetos, dada la perpetuación en el imaginario colectivo de un abanico limitado de estereotipos relativos al género femenino; la utilización que la publicidad realiza de las personas mayores propicia la consolidación de imágenes de carácter sesgado en torno a este grupo demográfico. Un sesgo que se hace más patente si se fija la atención en las representaciones publicitarias de las mujeres mayores; esto es, la configuración que la publicidad realiza de la vejez convenientemente filtrado con el definidor género. Ambos elementos, edad y género, participan en lo que Sontag denominó la doble afrenta y discriminación (Sontag, 1972) dado las vicisitudes vinculadas a la vejez, se incrementan por aquellas derivadas del hecho de "ser mujer".

La construcción social y publicitaria de las imágenes de las mujeres ha sido fundamentada, y en muchas sociedades perfectamente cimentada, en torno a los valores vinculados a lo corporal y a lo sensual. Una situación que ha llevado a Simone de Beauvoir $(1983 ; 2000)$ a señalar la existencia de una dimensión de género en la vejez.

Mientras que el hombre envejece de forma constante, la mujer se ve bruscamente despojada de su feminidad; todavía joven, pierde el atractivo erótico y la fecundidad, que le procuraban, a los ojos de la sociedad y a los suyos propios, la justificación de su existencia y sus oportunidades de felicidad: ahora le queda por vivir, privada de todo futuro, más o menos la mitad de su vida adulta... (Beauvoir, 2000: 377). 
El paso del tiempo provoca la paulatina pérdida de los atributos físicos sobre los que se construyó la identidad femenina, provocando la invisibilización de las mujeres mayores. Incluso antes de que los fenómenos de carácter fisiológico hayan marcado el fin de una etapa y el inicio de otra, se inicia el drama moral que supone el envejecimiento de la mujer desde una perspectiva social y antropológica (Beauvoir, 2000).

Los valores femeninos que tienden al alza en el mercado de los bienes simbólicos son la delgadez, la altura, la belleza y la juventud; por ejemplo, en un medio como la televisión resulta complejo "encontrar una presentadora de televisión que tenga ya una edad madura. Para la televisión [como sucede con la publicidad], en un momento determinado, la mujer se hace invisible” (Núñez y Loscertales, s/f). Esta invisibilidad no es más que un efecto del ageism (en español "etarismo" o "edadismo"), término entendido como discriminación sistemática basada en la edad, que fue acuñado por Butler (1969).

La invisibilización de la vejez, especialmente en lo que respecta a las mujeres, semeja resultar contradictorio en un momento en que la tercera edad se ha convertido en público objetivo de numerosos productos y servicios. La aparición de una serie de productos y servicios dirigidos al público de mayor edad, ha propiciado la inclusión en la publicidad de representaciones de la madurez, impensables hace solamente una década. No obstante, estas imágenes presentan una perversión mayor -si cabe- que la propia invisibilización, al mostrar a modelos femeninas más próximas a los cincuenta que a los sesenta años. La madurez sustituye a la vejez, en las representaciones publicitarias, tiñéndolas con una pátina de juventud que -incluso en sus postrimerías- se muestra como el ideal de la perfección femenina.

Las mujeres en estas edades aparecen esporádicamente en la publicidad, relegadas al papel de abuelas amantes que guardan recetas sabrosas o de suegras que admiran la limpieza de la casa o de la ropa. Es cierto que la vejez no entra habitualmente en los escenarios publicitarios, pero si además es una vejez "femenina” ( ... ) está prácticamente desterrada. (Pablos, de, 2005: 27-28)

El cuerpo anciano suele excluirse de la realidad publicitaria al no responder a los cánones estéticos dominantes, situándose próximo -sobre todo en el caso de las mujeres- a la compasión en lugar de a la seducción. Una situación que, siguiendo a Ferro (2009), va a propiciar ritos de ocultación que se proyectarán en los discursos publicitarios de los diferentes medios de comunicación; entre ellos el medio sonoro, objeto de este artículo.

\section{Contextualización del objeto de estudio y metodología empleada}

La representación de la vejez y, más concretamente, la vejez femenina en los diferentes medios de comunicación y en la publicidad, ha sido tratada por numerosos estudios de carácter nacional e internacional, alcanzando su mayor proyección a partir de la década de los 70 (a pesar de que, como recoge Lehr:1980, existen investigaciones en torno a la imagen de la vejez desde los años 50). Precisamente, este auge de las representaciones vinculadas a la vejez, se corresponde con la 
etapa en la que los teóricos del estereotipo social enfocaron su estudio a nuevos estereotipos, como los de género o aquellos relacionados con las edades de la vida, y a subestereotipos (Andrés, de, 2002).

Entre las investigaciones que abordaron el estudio de las representaciones de la vejez en medios de comunicación y publicidad se puede establecer dos grupos bien diferenciados: aquellas que hicieron de la estereotipia en función de la edad el eje de su trabajo (entre la que destacan clásicos como Aronoff: 1974, algunas más actuales como la de Gergen y Gergen: 2000, además de estudios en el ámbito español como el de Freixas: 1998), y aquellos otros que enfocados al análisis de otras realidades, como los estereotipos de género, tomaron la edad como elemento de estudio.

En lo que se refiere a las investigaciones en función del binomio edad-estereotipia de género, el estudio de las diferentes representaciones no ha dado lugar a un volumen de análisis equiparable. Si nos centramos en la edad o, más concretamente, en la etapa vital, a pesar de que el análisis de las representaciones mediáticas y publicitarias de la vejez ha dado lugar a un amplio volumen de análisis, dicho volumen es superado si atendemos a aquellas etapas vitales caracterizadas por la mayor vulnerabilidad de sus individuos, como es el caso de la infancia. En el caso de atender a las representaciones de género, el hecho de que la publicidad abuse de las imágenes femeninas, junto el alto grado de estereotipia implícito, ha propiciado que la mayor parte de los estudios llevados a cabo en torno al género en medios de comunicación y publicidad, hayan fijado su objetivo en las mujeres. Finalmente, atendiendo al medio-soporte analizado, tanto en el caso de las representaciones de la vejez, como en el caso de las representaciones de género, se puede destacar una hiperrepresentación de estudios relativos al medio televisivo, que contrasta con la infrarrepresentación de aquellos vinculados al medio radiofónico. No obstante, los escasos estudios llevados a cabo en torno a la materia han señalado que los patrones de parcialidad en el medio sonoro son similares a los de la televisión (Neto y Santos, 2004).

El objeto del presente trabajo ha sido el de conocer la presencia de mujeres mayores en la publicidad radiofónica, atendiendo al número de personajes, tipo de representaciones, rol desempeñado y tono del mensaje.

Para conseguir dicho objetivo, se ha llevado a cabo un análisis de contenido de la publicidad radiofónica presentada al Festival Publicitario de San Sebastián, desde la creación del galardón de radio (1996) hasta su apertura al mundo latino como El Sol, Festival Iberoamericano de la Comunicación Publicitaria (2003). Esto supone la configuración de un universo de análisis, de un total de 915 piezas.

La selección de este festival se basó en el hecho de que durante años fue el certamen de referencia del sector publicitario español, por lo que las piezas presentadas a concurso suponen la excelencia de la creatividad made in Spain y, por tanto, las representaciones implícitas en sus mensajes pertenecen al imaginario colectivo español.

Una vez determinado el universo de estudio, se seleccionaron aquellas cuñas radiofónicas en las que apareciese representada, de algún modo, alguna voz femenina, lo que redujo el número de cuñas a $379(41 \%)$, y que destaca la escasa presencia de voces femeninas en la publicidad radiofónica, frente a las masculinas. 
La muestra final, en busca de seleccionar solamente aquellos anuncios radiofónicos con presencia de personajes femeninos cuya voz o rol desempeñado delatase senectud, quedó constituida por un total de trece anuncios (1,5\%). Una muestra limitada sobre la que se trabajó con una herramienta de análisis construida tomando como base la propuesta por el clásico estudio de McArthur y Resko (1975).

Previamente al estudio empírico propiamente dicho, se llevó a cabo una selección entre los personajes del anuncio, en busca de establecer una metodología para aplicar la ficha de trabajo con el menor porcentaje de error posible. Para ello se tomó como referencia el citado estudio de McArthur y Resko (1975), llevando a cabo el análisis en cuestión sobre aquellos dos personajes principales del anuncio; incluso en aquellos casos en los que la voz femenina no se correspondía con ninguno de los dos protagonistas. En aquellas cuñas en las que la selección de los dos personajes principales creó algún tipo de controversia, se primó la selección de las voces femeninas como personajes principales frente las masculinas. De este modo se promovió la sobrerrepresentación femenina, con la finalidad de basar la imagen de las mujeres en la publicidad radiofónica presente en un número importante de anuncios, estimulando de este modo, su mayor representatividad.

Asimismo, los resultados obtenidos han sido comparados con las tres principales conclusiones que, siguiendo a Freixas (1998), se han podido extractar de las investigaciones llevadas a cabo en torno a las imágenes de los mayores -especialmente de las mujeres mayores- en los medios de comunicación y publicidad. Dichas conclusiones han sido utilizadas a modo de hipótesis de partida de este trabajo:

Las personas mayores y las mujeres se representan en los medios de comunicación en un número desproporcionadamente bajo;

La realidad de sus vidas está distorsionada y en absoluto reflejan su realidad;

Las mujeres suelen representarse de manera menos favorable que los hombres de su misma edad.

Unas hipótesis que como se demostrará a continuación, saldrán reforzadas tras el análisis de las representaciones de mujeres mayores en la publicidad radiofónica analizada.

\section{Del estereotipo publicitario a la estereotipia sonora}

Luhmann (2000) señaló que los medios de comunicación reconstruían la realidad social a partir de tres elementos interdependientes: la información, la publicidad y el entretenimiento, entre los que se ha destacado la publicidad -concretamente la radiofónica- para conocer las representaciones en torno a la vejez femenina.

En la sociedad contemporánea, la publicidad se configura como uno de los agentes más influyentes, lo que la va a convertir en un marco de referencia fundamental para el análisis de las representaciones social. De este modo, la publicidad se convierte en un indicador de las condiciones de igualdad o desigualdad social, debido a que el mundo que recrea sus anuncios 
refleja un reparto de papeles y un determinado ajuste entre los roles sociales asumidos por los diferentes grupos sociales en el mundo real, al tiempo que transmiten a su audiencia una propuesta determinada; un modelo a imitar (Pablos, de, 2005).

Desde el punto de vista de la utilidad, la publicidad va a construir una serie de imágenes idealizadas, destinadas a atraer, y que van a asociarse a determinados productos y estilos de vida. Por esta razón es interesante analizar el tratamiento que los mensajes publicitarios le dan a determinados colectivos, como el de la tercera edad, la tipología de estereotipos que utilizan para referirse a esa realidad y, más concretamente, las motivaciones que lleva a creativos y anunciantes a seleccionar unos estereotipos en detrimento de otros.

Este estrecho vínculo que presentan los estereotipos con los medios de comunicación y la publicidad, ha sido puesto de relevancia desde el momento mismo de la primera conceptualización del término como pictures in the mind (Lippmann, 2004). Los mensajes mediáticos y publicitarios van a sacar el mayor partido posible de la extraordinaria capacidad comunicativa que presentan dichos estereotipos, capaces de condensar en imágenes concretas la enorme complejidad y diversidad social. El mayor peligro lo constituye el hecho de que "tales estereotipos afectan a las percepciones de quienes comparten el sistema de creencias, con independencia de las características individuales de las personas que integran el grupo estereotipado, y pueden llegar a influir sobre los comportamientos y actitudes de dichas personas" (González-Solaz, García-Cubelles y Ortega, 2003: 2).

En el caso concreto de la publicidad radiofónica, y al igual que sucede con otros medios de comunicación, acude a un limitado abanico de estereotipos que le permita construir sus mensajes. Sin embargo, al igual que los anuncios televisivos o la publicidad gráfica se valen de atributos visuales para construir sus representaciones, los mensajes radiofónicos deberán acudir a una serie de atributos sonoros.

De modo independiente a la presencia de estos estereotipos, el medio radio presenta una situación comunicativa muy particular que la dispone cercana a su audiencia a la vez que impregna en ella sus mensajes; virtudes que quedan eclipsadas ante la -aparente- ausencia de imagen de la radio. Aparente, porque si se utiliza correctamente las posibilidades expresivas del medio se puede llegar a sacar el mayor partido al poder evocador del medio posibilitando la visualización de la situación comunicacional y activar el recuerdo; "la radio en color" de Betés (2002: 40). Para ello la radio cuenta con la imaginación como principal alidada, a la que apela con la utilización de una serie de elementos que susciten un recuerdo, a la vez individual-colectivo, en las mentes de los oyentes. Imágenes compartidas sobre las que se asentarán los estereotipos publicitarios. "La imagen de una palabra, el escenario mental al que alude, queda cerrado por similitud o oposición con la imagen mental construida por la música, por los sonidos o por otra palabra; y superpone su expresión fónica con la primera (García García, 2000: 30-31).

En definitiva todo lo visual puede tener su representación sonora, al tiempo que todo el sonido puede representarse mediante imágenes. Las representaciones radiofónicas, en especial aquellas vinculadas a las mujeres mayores, se asoman a un espejo sin imágenes que serán reconstruidas por los oyentes con las pistas que le facilita el medio. 


\section{La construcción de personajes sonoros}

Una de las posibilidades que el medio radiofónico presenta a la hora de construir sus relatos publicitarios, es la de convertir una voz en una reconstrucción mental del emisor; reconstrucción dotada de atributos de carácter físico como aquellos otros de carácter psicológico.

Para el receptor de un determinado mensaje radiofónico, cuya emisión supone un estímulo sonoro en el que el medio impone la eliminación de toda imagen física (con la consecuente información gestual); el movimiento melódico, tímbrico y rítmico de las palabras pasa a ocupar el lugar de las imágenes. Unas imágenes que el receptor contribuye a construir con la aportación de su propia imaginación. "Mediante el sonido de su voz, el narrador sugiere al radiooyente un tipo determinado de perspectiva visual, de luminosidad, de textura, de grado de tensión, de movimiento" (Rodríguez Bravo, 1989: 64). Estos constructos mentales a partir de un determinado estímulo sonoro, pueden llegar a tal grado de definición que incluso se pueden aproximar al concepto de "iconicidad".

El sonido y la voz, en cualquier caso, pero especialmente dentro del mensaje radiofónico, son unos de los instrumentos más eficaces que existen para estimular la emotividad del ser humano. Son capaces de generar una impresión emocional que permite la vinculación emisor-receptor de los caracteres acústicos de la voz que escucha. De este modo, la "ceguera" del medio radiofónico configura un nuevo espacio expresivo que va a estar dominado por el sonido. Un espacio en el que, inmerso dentro del proceso de revisión y de revalorización de todas las fuentes de información no visuales, se va a desarrollar la expresión fonoestésica (Rodríguez Bravo, 1989). Denominación por la que se conoce la expresividad sonora transmitida por medio de determinados rasgos de la voz, que permite la comunicación de información sobre gesticulación, actitud, carácter, aspecto físico y contexto del emisor. Esta reconstrucción mental, fundamentada en características propias de la expresividad sonora va a presentar dos particularidades: por un lado es compartida por un grupo de oyentes (característica con la que se desmitifica la idea de que cada oyente se construye su propia imagen mental de una voz), por otra permitirá una asociación automática, solamente interrumpida con el desplazamiento de la imagen auditiva por la real.

La publicidad radiofónica acude a un número limitado de representaciones femeninas que, debido a las particularidades que el medio presenta, responde a un abanico menos plural y más previsible en busca de alcanzar una mayor comprensión. Las cuñas de radio acuden a personajes con roles más marcados, que se encuadran en situaciones especialmente previsibles. Ante la ausencia de riqueza visual de la televisión o la publicidad gráfica, la radio construye los escenarios con sonidos y músicas totalmente reconocibles en busca de asegurar la mayor comprensión de la escena por parte de sus públicos.

Si el proceso de estereotipia sonora se basa en el uso de un conjunto de recursos auditivos a partir de los cuales se logra suscitar una serie de imágenes mentales, resulta interesante saber qué recursos podrían estar implicados en la estereotipia de los personajes femeninos de edad avanzada. El conocimiento de estos recursos será de utilidad para determinar cuáles de ellos serán 
relevantes para conseguir que la caracterización de los estereotipos objeto de estudio, pueda desarrollarse de manera instantánea y unívoca dentro de una comunidad de oyentes. En este sentido, al igual que los atributos visuales de los personajes en los medios gráficos o audiovisuales describen el tipo de rol que desempeñan, la voz, el lenguaje o el discurso van elementos definitorios de los estereotipos en la publicidad radiofónica.

Si se atiende al objeto concreto de estudio, se puede simplificar el número de elementos implicados en la construcción sonora de las representaciones femeninas en torno a la vejez a un solo definidor: la voz y sus parámetros, entre los que destaca el timbre. Elemento que resulta fundamental, para la construcción de las representaciones de otros colectivos relacionados con una determinada etapa vital, como la infancia o la adolescencia.

En efecto, el timbre constituye el rasgo más definitorio de la voz humana; lo que la dota de personalidad. Por esta razón, además de caracterizar una voz concreta, se mueve en torno a unos parámetros según el grupo al que pertenezca: los hombres y los ancianos suelen presentar timbres más graves, mientras que los correspondientes con las voces femeninas e infantiles resultan más agudos. Esta característica, además permitir la diferenciación entre unas voces y otras, posibilita reconocer el sexo y la edad de los hablantes, lo que lo ha configurado como una característica idónea para abordar esta investigación.

Al mismo tiempo, el timbre conlleva determinadas características de tipo cultural que definirán, de un modo más o menos consciente, al personaje al que pertenecen. En este sentido, resulta frecuente la consideración de las voces más agudas como poco aseverativas en sus exposiciones (MacDonald, 1995), frente a la credibilidad de aquellos timbres más graves. Esta situación ha propiciado la utilización de voces graves para caracterizar a aquellos personajes dotados de autoridad, como sucede en el caso de los prescriptores publicitarios, independientemente de si se trata de voces femeninas o masculinas.

\section{Mujeres mayores en la publicidad radiofónica española}

A la hora de abordar aquellas representaciones que, de las mujeres mayores, incluyen los anuncios radiofónicos presentados al Festival de San Sebastián (entre 19963 y 2002, ambos inclusive) el elemento que llama más atención es su escasa presencia. Una escasa presencia que se ha podido deducir de la comparación del volumen de cuñas pertenecientes al universo del estudio (915) con las que, finalmente, compusieron la muestra de análisis (13).

En efecto, como se puede observar en el gráfico, el número de cuñas de la selección de estudio que cuentan con voces femeninas supone menos de la mitad del universo total de análisis. Una presencia escasa, en relación con la hiperrepresentación de las voces masculinas, que se agudiza cuando se opta por cruzar estos datos con el indicador vejez: solamente presente en el 1,5\% de la selección. 
Gráfico 1. Universo y muestra de estudio (fuente: elaboración propia).

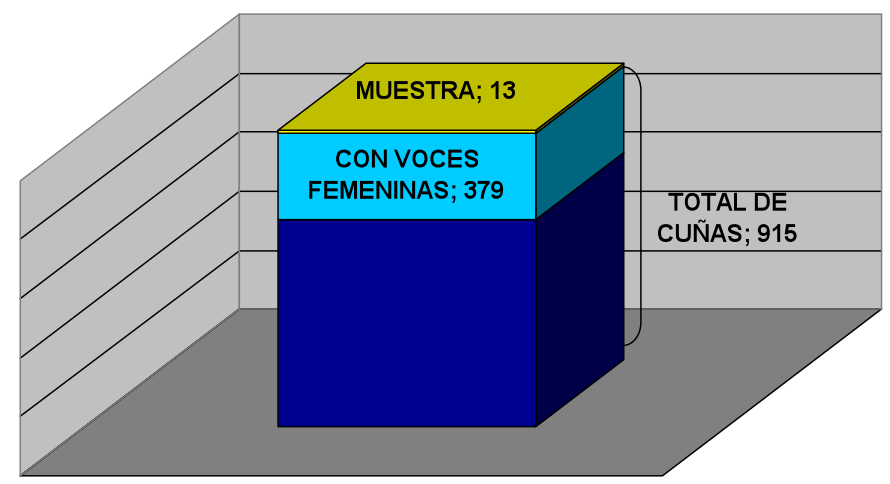

La escasa utilización por parte de la publicidad radiofónica de representaciones de mujeres mayores, no sólo no es exclusiva de esta colectividad, sino que aparece relacionado con otros grupos conformados a partir de su pertenencia a una determinada etapa vital como es el caso de la infancia.

Gráfico 2. Porcentaje de personajes femeninos en función de la edad (fuente: elaboración propia).

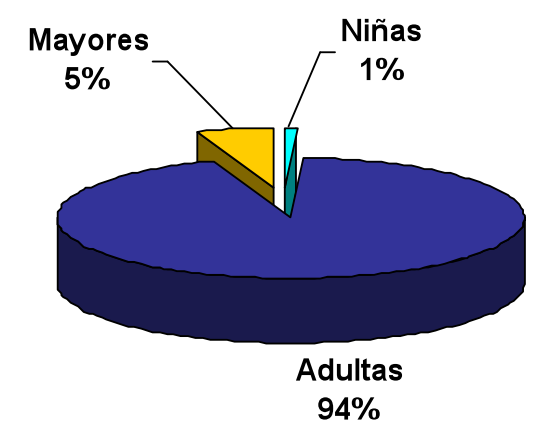

Mayoritariamente, las representaciones de las que se vale el discurso publicitario radiofónico, como sucede con los restantes medios de comunicación, suelen corresponderse con las imágenes de hombres y mujeres adultos. Al hablar de "adulto/a" se hace referencia a un definidor amplio que incluirá, prácticamente, a todos los personajes publicitarios situados entre la infanciaadolescencia y la vejez; y que en el caso de las representaciones femeninas, la exigencia de la juventud y la belleza, va a propiciar que las mujeres adultas se encuentren más próximas a los veinte años que a los cuarenta.

En el caso concreto de la publicidad radiofónica, se puede hablar de un ligero incremento en la edad de los personajes femeninos respecto a otros medios fundamentados en la imagen como la 
televisión o la publicidad gráfica. Dicho incremento de la edad de las voces que conforman a esas mujeres adultas puede relacionarse con dos elementos relevantes de la comunicación publicitaria:

Por una parte, la necesidad de mostrar imágenes deseables, basadas en belleza y juventud ha propiciado que la publicidad acuda, al igual que la moda, a modelos femeninos cada vez más jóvenes. Mujeres que, prácticamente sin haber superado la pubertad, se van a convertir en adultas gracias a la magia de la publicidad; una publicidad que las va a convertir en modelos de referencia, a los que se asomarán las mujeres reales que, aún con la consideración social de jóvenes, les duplican la edad.

Por otra parte, las connotaciones vinculadas en la comunicación radiofónica a la utilización de voces graves y agudas, ha propiciado la utilización en la publicidad sonora de timbres más graves en busca de una mayor credibilidad del anuncio. Como uno de los elementos influyentes en la mayor o menor gravedad de una voz, es la edad, la publicidad radiofónica acude a mujeres adultas reales. Pero no se debe confundir adultas con mayores; de hecho, la mayor parte de las imágenes mentales que se han construido a partid de una voz femenina, se corresponden con expresiones fonoestésticas de mujeres jóvenes (entendiendo la juventud desde un punto de vista social).

No obstante, resulta complejo encontrar una explicación razonable a la marcada diferencia entre la utilización de voces masculinas y femeninas en la publicidad radiofónica, así como al predominio de la utilización de voces adultas frente a otras cuyo timbre se asocia con la infancia o la madurez-vejez. Esta explicación resulta todavía más compleja si se atiende al hecho de que el objeto de estudio, la publicidad radiofónica presentada al Festival de San Sebastián, presupone una creatividad y originalidad que la eximen de tener en cuenta los estereotipos asociados a determinados tipos de voces que resultan esenciales en la publicidad radiofónica tipo (Perona y Barbeito, 2008), donde predomina el elemento informativo.

Otro de los elementos que se han analizado para indagar en el tipo de representaciones que la publicidad sonora realiza de las mujeres mayores, es el tipo de rol desempeñado por dichos personajes dentro del relato. Para conocer esta realidad, se ha traspasado el objeto de análisis de las cuñas a los personajes, situación que ha configurado una muestra de estudio de un total de 18 individuos.

La idea de partida era que el conjunto de papeles en los que se sitúa a las mujeres mayores dentro del relato radiofónico, al igual que sucede en otros medios, se vincularía a la concepción de abuela tradicional; desde la dispensadora de cuidados, hasta la artesana de productos de calidad. Sin embargo, el estudio de la muestra reveló un interesante catálogo de roles, entre los que la incidencia de la abuela era prácticamente circunstancial.

En efecto, y a pesar del pequeño tamaño de la muestra, se puede destacar hasta seis roles diferentes (además de "otros") que desempeñan las mujeres mayores dentro de los anuncios radiofónicos. Entre ellos, el más numeroso es el de "papel”; entendido como la reproducción en los personajes del anuncio de características propias de celebridades de la ficción con las que el público está especialmente familiarizado (por ejemplo Jane, Escarlata O'Hara, Caperucita Roja, etc.). En este caso se trata de las protagonistas de Las Chicas de Oro, una comedia bastante famosa (sobre todo si nos situamos en la década de los 90) cuya singularidad radica en estar 
protagonizada por cuatro mujeres mayores. La utilización de las voces de Rose y de Dorothy, y la presencia "fuera de campo" de Sophie, para publicitar una residencia de la tercera edad suponen otra particularidad de estas cuñas radiofónicas; dada la especificidad del servicio anunciado.

Gráfico 3. Tipología de roles presentes en la muestra de estudio (fuente: elaboración propia).

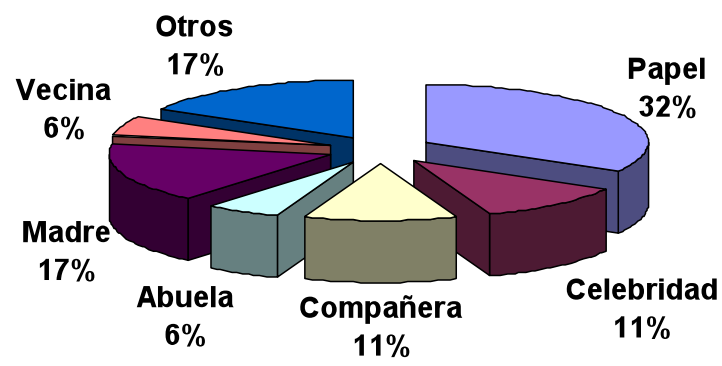

Otro de los roles más utilizados, con el mismo número de personajes que el de compañera, es el de celebridad de la vida real. En la muestra analizada, existen dos personajes cuyos rasgos fónicos y expresivos permiten su reconocimiento con dos famosas, ambas en edades maduras, habituales de la prensa rosa: Carmen Sevilla (cantante, actriz y presentadora) y la Duquesa de Alba (noble).

La utilización de este tipo de roles, papel y celebridad de la vida real, está estrechamente vinculada a las posibilidades que el medio radiofónico presenta. Frente a otros medios que precisan alimentarse de imágenes físicas, la radio puede valerse de las voces de profesionales del doblaje o imitadores para, mediante la reproducción de una serie de rasgos fónicos o lingüísticos con los que está familiarizado su público objetivo, conseguir generar en la mente del oyente la imagen del personaje famoso en cuestión.

Por otra parte, otros roles que resulta de especial interés dentro de la selección objeto de estudio son los de abuela y madre. El primero, que se corresponde con uno de los escasos estereotipos sobre la vejez presentes en los mensajes publicitarios, tiene una presencia prácticamente testimonial en la muestra de estudio; está representado pero solamente en una cuña. El segundo, el de madre, no se corresponde con dicho estereotipo publicitario debido a su construcción en torno a la vejez (propia) y a la madurez de sus hijos; construcción que choca con la representación habitual de la maternidad, basada en la juventud, la belleza y el cuidado de los niños. Sin embargo, la relación que guardan las madres mayores con sus hijos no se trata solamente de un vínculo parental, sino que desarrolla características del estereotipo como la preocupación o la hiperprotección por sus hijos. La conjugación de esta representación con el tono humorístico de la mayor parte de los anuncios estudiados, tiene como resultado una caricatura de madre perfecta: se dedica en cuerpo y alma a su hijo, celebra sus avances y lo 
defiende sobre todas las cosas. Circunstancias que resultan irrisorias de tener en cuenta la edad de ambos.

Finalmente, como parte del codificador "otros", resulta interesante comentar la existencia de un estereotipo de mujer mayor, completamente diferente a los ya mencionados, que se caracteriza por la relación que establece con un personaje masculino dentro del relato. Se trata del de mujer mayor, incluso anciana si se tienen en cuenta las características de su voz, que se deja encandilar por un amante joven. En la voz de este joven, el público objetivo podría construir la imagen de un habitual de la prensa rosa del momento, cuya carrera fulgurante rosa se había iniciado a raíz de su relación con una mujer mayor vinculada a la industria del espectáculo. La construcción del personaje femenino de la cuña utiliza alguna de las características propias de las imágenes mediáticas en torno a la vejez: voz temblorosa, dificultades expresas para reconocer a su interlocutor y/o para comprender su discurso, vulnerabilidad, soledad, etc. Unas características que subrayan la contraposición existente con el joven "cazafortunas", dotándola de un tono humorístico.

En este sentido, otra de las categorías analizadas es la del formato creativo en el que se van a desarrollarlos mensajes publicitarios para alcanzar unos resultados concretos; categoría que presenta una influencia importante en el tipo de roles desempeñados por las mujeres mayores de la muestra.

Gráfico 4. Formatos expresivos presentes en las cuñas analizadas (fuente: elaboración propia).

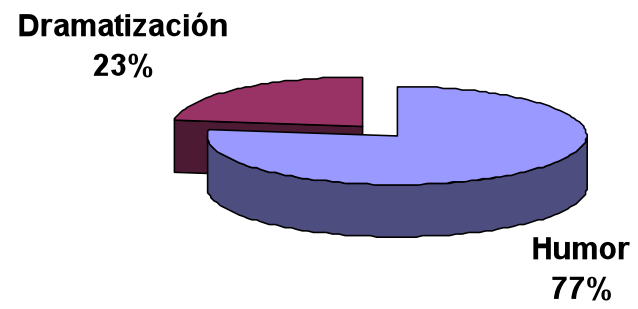

Con la finalidad de alcanzar los objetivos previstos, el discurso publicitario se va a valer de diferentes estructuras que sustentarán el contenido del mensaje que, a través de un proceso creativo se ha convertido en un concepto (Muela: 2001). Una tipología de estructuras que no se desarrollarán en la cuña en estado puro, debido a que existe una tendencia hacia el hibridismo de formatos, pero que se presentarán cerradas para facilitar el análisis y la clasificación de la muestra (narración, dramatización, fragmento de vida o jingle). A esta tipología clásica de formatos expresivos se ha incorporado el humor, dado su enorme peso en el conjunto de cuñas presentadas al Festival Publicitario de San sebastián.

En el caso concreto de la selección objeto de estudio, solamente se han señalado dos tipologías de formato expresivo: la dramatización y el humor. En efecto, tal como se puede observar en el 
gráfico anterior, existe una hiperrepresentación del humor como formato creativo; hiperrepresentación que es común a todo el universo de análisis pero, que en el caso concreto de la muestra de estudio, adquiere mayor presencia.

El enorme peso del humor en los mensajes publicitarios aparece reflejado en sus contenidos, aparentemente poco serios, que permiten la construcción de determinadas situaciones y/o personajes con relativa impunidad, al tiempo que permite ciertas licencias creativas. Tal es el caso, por ejemplo, de la caricaturización de las madres ancianas, o la utilización de determinados famosos con la finalidad de parodiar a aquellas celebridades, cuyo peso como líderes de opinión, los ha convertido en cotizados prescriptores publicitarios.

Además del humor, el otro formato expresivo presente en la muestra de estudio es el de dramatización; formato que se corresponde en su totalidad con los tres anuncios publicitarios protagonizados por Las Chicas de Oro.

Finalmente, si atendemos a otras realidades analizadas, como el sexo de la voz over o del personaje que inicia la interacción publicitaria, la localización espacial, la utilización de argumentos o el tipo de productos anunciados (salvo el caso concreto de la residencia de ancianos anteriormente citada) no existen resultados de especial relevancia para la construcción de imágenes en torno a la vejez femenina dentro de la cuña radiofónica.

\section{Conclusiones}

El trabajo desarrollado en torno a las representaciones de la vejez femenina en la publicidad radiofónica española, ha permitido profundizar en la construcción y utilización de imágenes de mujeres mayores por parte de la publicidad.

El análisis de la presencia de esta tipología de imágenes en la publicidad sonora ha permitido corroborar, al igual que otros estudios precedentes (llevados a cabo en otros medios de comunicación), la práctica invisibilidad de representaciones de mujeres mayores en la publicidad. Esta infrarrepresentación de imágenes en torno a la vejez femenina en los anuncios radiofónicos presenta, sin embargo, una tendencia similar a otra colectividad constituida a partir de una etapa vital: la infancia.

A pesar de su escasa presencia en el universo de análisis (1.5\%), las representaciones femeninas de la vejez en la publicidad sonora presentan una mayor variedad respecto a su concepción tradicional en torno a la "abuela". No obstante, esta variedad de imágenes, todavía no se corresponde con la realidad social.

Frente a la construcción tradicional que la publicidad realiza de la vejez femenina, los anuncios sonoros propone una mayor variedad de roles. Una propuesta que va a basarse en las posibilidades del medio radiofónico para la construcción de personajes, cuyos rasgos fónicos y expresivos permitan su identificación con celebridades conocidas (ya sean celebridades del mundo real, ya personajes de ficción). 
La mayor utilización del humor como formato expresivo va a influir en la construcción de determinados personajes y/o situaciones con una cierta comicidad; como sucede con el caso de las madres ancianas, cuya relación con sus hijos se puede determinar como una parodia del ideal publicitario de maternidad.

Asimismo, si se comparan los resultados obtenidos del análisis del objeto de estudio con aquellos aportados por Freixas (1998) que fueron tomados como hipótesis de partida del trabajo, se puede confirmar que:

Las personas mayores y las mujeres se representan en la radio, al igual que en otros medios de comunicación, en un número desproporcionadamente bajo.

La realidad publicidad en la que se representan no se corresponde, en su mayor parte, con la realidad social.

La ausencia en la muestra de estudio de imágenes relativas a hombres mayores (solamente representados en la selección por un personaje masculino) ha impedido corroborar o refutar la tercera hipótesis; esto es "las mujeres suelen representarse de manera menos favorable que los hombres de su misma edad".

En definitiva, la publicidad radiofónica, al igual que sucede con otros medios, destierra de sus mensajes aquellas representaciones vinculadas con la vejez y, especialmente, con la vejez femenina. Esta escasa presencia, sin embargo, presenta características propias en cuanto a la representación de las mujeres mayores como un grupo no homogéneo, que desempeñan papeles diferentes al de la abuela clásica. No obstante, dichas representaciones publicitarias aún difieren de la realidad social de la llamada "tercera edad"; aún cuando este colectivo está configurándose como un grupo de consumidores potente.

\section{Referencias}

Andrés, S. de (2002). Estereotipos de género en la publicidad de la Segunda República Española. Crónica y Blanco y Negro. Tesis de doctorado. Dir. D. Eguizábal. Universidad Complutense de Madrid. Obtenida el 12 de septiembre, 2007, de http://www.ucm.es/eprints/4601/

Aronoff, C. (1974). "Old age imn prime time”. Journal of Communication No 24. pp. 86-87.

Beauvoir, S. de (1983). La vejez. Barcelona: Edhasa.

------ (2000). El segundo sexo. Madrid: Cátedra.

Betés, K. (2002). El sonido de la persuasión. Relatos publicitarios en la radio. Valencia: Universidad Cardenal Herrera-CEU.

Butler, R. N. (1969). “Age-ism: another form of bigotry”. The Gerontologist No 9. pp. 277-279.

Durán, M. A. (2006). "Las fronteras sociales del siglo XXI” En Morant, I. [dir. ] Historia de las mujeres en España y América Latina. Del siglo XX a los umbrales del XXI. Madrid; Cátedra. Vol. IV. 
Freixas, A. (1998). "La mires como la mires, no las verás. El doble estándar del envejecimiento en la publicidad televisiva”. Comunicación y Cultura. No3. 29-40.

García García, F. (2000). "La publicidad en radio: Imágenes de baja intensidad retórica”. En M. Fernández Areal (Dir. ) La publicidad en radio. Pontevedra: Deputación Provincial de Pontevedra.

Gergen, K. J. \& Gergen, M. M. (2000).” The new aging: self construction and social values”. Obtenido el 10 de marzo, 2007 de http://www.swarthmore.edu/SocSci/kgergenl/ newaging.html

González-Solaz, M. J.; García-Cubells, C; Ortega, A. (2003). “Análisis de tendencias expresadas de la variable género en la comunicación publicitaria”. Obtenido el 22 de febrero, 2008, de http://www.campusrnet/forouniversitario/pdfs/Comunicaciones/Publicidad_y_Marke ting/M_Jose_Gonzalez.pdf

Lehr, U. (1980). Psicología de la senectud. Barcelona: Herder.

Lippmann, W. (2002). La Opinión Pública. Madrid: C. de Langre.

Luhmann, N. (2000). La realidad de los medios de masas. Barcelona: Anthropos.

MacDonald, M. (1995). Representing Women. Miths of Feminity in the Popular Media. Londres: Edward Arnold.

McArthur, L.; Resko, B. G. (1975). "The portrayal of men and women in American television commercials”. The Journal of Social Psychology No 97. pp. 209-220.

Neto, F. e Santos, A. (2004). "Gender Role Stereotyping in Radio Advertisements: a Portuguese and Cross-national Analysis”. Journal of Radio Studies No1. vol.11.pp. 131- 145.

Pablos, J. M. de (Dir.). (2005). "Los nuevos modelos de mujer y de hombre de la publicidade televisiva actual”. Tenerife: Equipo Latino de Comunicación Social. Obtenido el 15 de enero, 2009, de http://www.eccc.ucr.ac.cr/pdfs/consejocataluna.pdf

Parales, C.J. y Dulce-Ruiz, E. (2002). "La construcción social del envejecimiento y de la vejez: un análisis discursivo en la prensa escrita”. Revista Latinoamericana de Psicología Vol. 34 № 1-2.pp. 107-121.

Perona, J. J. y Barbeito, M. L. (2008). “El lenguaje radiofónico en la publicidad del prime time generalista. Los anuncios en la «radio de las estrellas”. Telos. Cuadernos de Comunicación e Innovación No 77. Obtenido el 15 de febrero, 2009, de http://www.campusred.net/telos/articulodocumento. asp?idArticulo=1\&rev=77

Rey, G. (1999). “Reflexiones sobre comunicación y envejecimiento”. Bogotá, Colombia. Ponencia presentada en el coloquio Periodismo para todas las edades. AIG de Colombia, Naciones Unidas y Universidad Javeriana.

Rodríguez Bravo, A. (1989). La construcción de una voz radiofónica. Tesis de doctorado. Barcelona: Universidad Autónoma de Barcelona (Microfichas).

Santiso, R. (2001). "III. El Cuerpo del delito. Torturas culturales en torno al cuerpo”. En M. Azpeitia, M. J. Barral, L. E. Díaz, T. González Cortés, E. Moreno e T. Yago (Eds.). Piel que habla. Viaje a través de los cuerpos femeninos. Barcelona: Icaria. 
Sontag, S. (1972). “The Double Standard of Aging”. Saturday Review of Literature No 95. pp. 2938. 